\title{
REFUGIADOS DE GUERRA E IMIGRAÇÃO PARA O BRASIL NOS ANOS 1940 E 1950 Apontamentos
}

\author{
Odair da Cruz Paiva*
}

\section{INTRODUÇÃO}

O tema da imigração para o Brasil deve ser pensado enquanto um processo que se intensificou no final do século XIX e que continua presente até os dias atuais. Entretanto, trata-se de um tema que não deve ser pensado de maneira uniforme; em linhas gerais, podemos identificar ao menos três fases distintas da imigração para nosso país até os anos 1950 .

A primeira fase (1888-1929) compreende o período da abolição formal da escravidão e a grande crise da cafeicultura em fins dos anos 1920. Nela, houve uma ênfase na inserção de imigrantes europeus e asiáticos, cujo norte foi o do abastecimen- to de braços para a lavoura do café. Neste período, a imigração para nosso país foi tratada - particularmente em São Paulo como política de mão-de-obra; aproximadamente 2.800 .000 estrangeiros entraram no período entre 1886 e 1915 (Boletim do Departamento Estadual do Trabalho, 1929).

Entre o final da I Guerra Mundial até o início dos anos 1930, a imigração de europeus tendeu a refluir significativamente, como demonstra o gráfico que se segue e, a partir dos anos 1930 ela já era pouco expressiva - se comparada com as décadas finais do século XIX e os dois primeiros decênios do século XX.

A partir dos anos 1930, e como resulta- do da depressão econômica provocada pelo crack da Bolsa de Valores de Nova Iorque, e também em virtude da ascensão dos regimes nazi-fascistas na Europa, houve uma reorganização das formas de reprodução do capital em nível mundial. A Divisão Internacional do Trabalho (D.I.T) estruturada desde o século XIX que supunha a existência de padrões de acumulação de capital diferenciados e combinados ( países de economia industrial e países de economia agro-exportadora) tendeu a uma reorganização.

Esta antiga D.I.T., entretanto, produziu um dos maiores deslocamentos populacionais de nossa história. No pano-

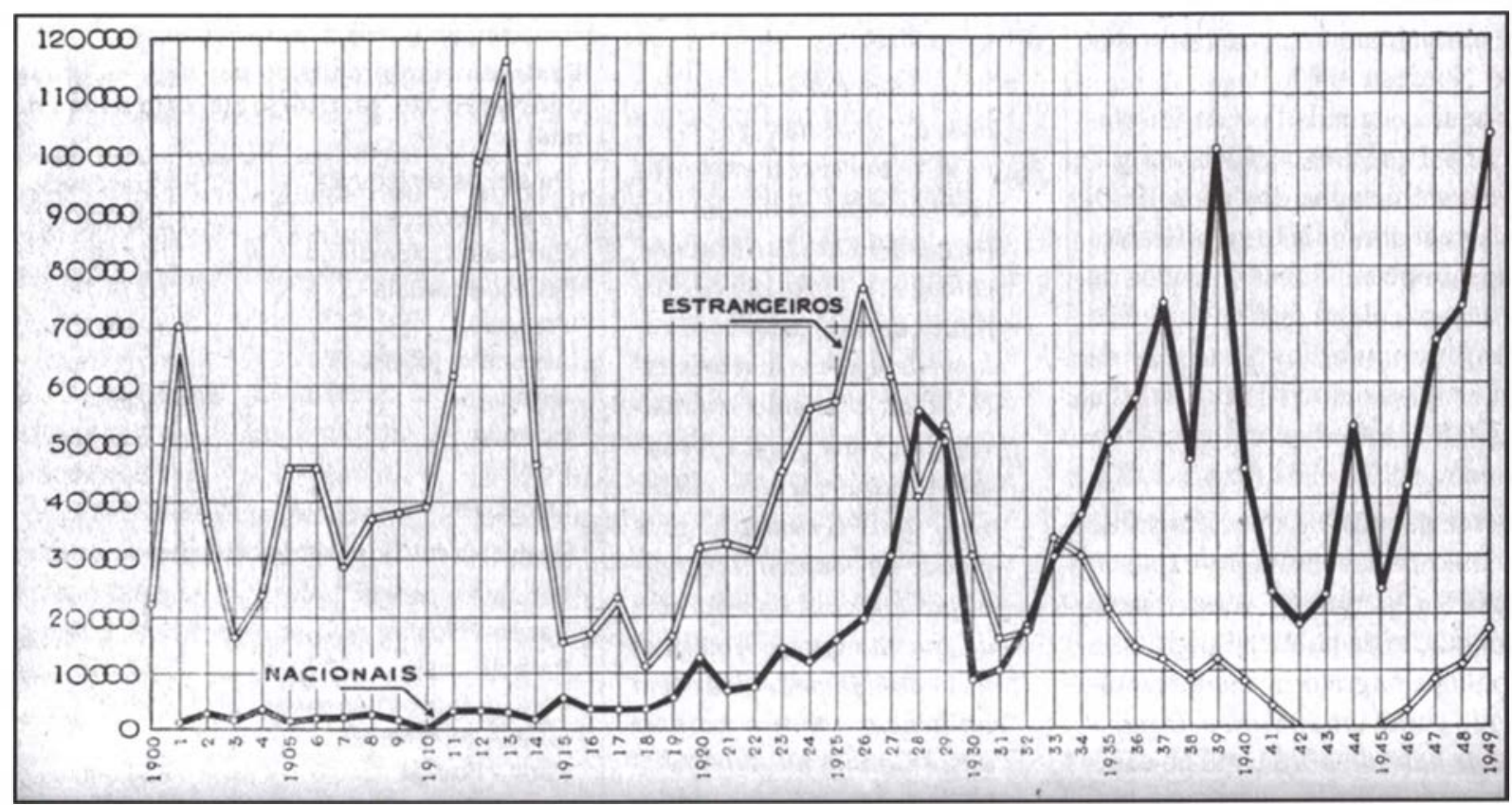

Fonte: Boletim da Diretoria de Terras, Colonização e Imigração. São Paulo: Secretaria da Agricultura, $n^{2}$ 5, dez/1950. 
rama europeu, processos de modernização econômica intensos em países como a Alemanha, Itália e também no Japão, dentre outros, engendraram um excedente populacional exportável para a América cuja cifra atingiu pouco mais de 48 milhões de pessoas, computando somente a imigração para os E.U.A., Canadá, Argentina e Brasil no período entre 1820 a 1915 (Boletim do Departamento de Imigração e Colonização, 1950).

No continente americano esta população foi absorvida tanto pelos E.U.A. quanto por países como o Brasil e Argentina que se inseriam na D.I.T. como fornecedores de produtos primário-exportáveis (café, carne, cereais...) Assim, acreditamos numa estreita relação entre os processos de deslocamentos populacionais e as dinâmicas diferenciadas de reprodução do capital tanto na Europa quanto na América.

O refluxo da imigração pós 1930 deve, entretanto, ser compreendido também como resultado da constituição - em alguns dos principais países exportadores de mão-de-obra como a Alemanha, Itália, Portugal, Espanha e Japão - de regimes autoritários e nazi-fascistas, os quais passaram a inibir as políticas de emigração. Este quadro fez com que a política de mão-de-obra para o abastecimento da lavoura paulista (fundamentalmente a cafeicultura e a cotonicultura) nas décadas seguintes notadamente até os anos 1950 - fosse orientada para a introdução de trabalhadores migrantes, oriundos em sua maioria dos Estados do Nordeste.

Temos aqui a segunda fase da imigração para o Brasil que, à exceção da imigração japonesa até meados dos anos 1930, foi marcada pela diminuição significativa do fluxo de europeus. Segundo dados da Secretaria da Agricultura do Estado de São Paulo, foram encaminhados para as lavouras de café e algodão do interior paulista, mais de 1.300.000 trabalhadores migrantes no período entre 1927 a 1951 (Paiva, 2000).

A escassez da mão-de-obra imigrante para o trabalho na lavoura agro-exportadora no país foi, portanto, equacionada com a reorientação da política imigratória para uma política migratória; compreendida no período como uma política de nacionalização de mão-de-obra tanto no campo quanto nas atividades urbano-indus- triais o que, em princípio, fechava as portas para um novo e intenso fluxo imigratório.

\section{REFUGIADOS E A NOVA IMIGRAÇÃO A PARTIR DOS ANOS 1940}

Ainda nos anos 1930, surgiu a preocupação com o crescente número de refugiados na Europa e sobre as possibilidades de sua realocação. Segundo dados da Liga das Nações, (Traft, 1936) em 1935 havia aproximadamente 970.000 refugiados na Europa, dos quais, a grande maioria era composta por alemães, russos, judeus alemães e republicanos espanhóis.

$\mathrm{O}$ avanço dos regimes totalitários na Alemanha, Itália e Áustria e a tomada do poder pela direita na Espanha, foram os fatores responsáveis pela produção de uma população que, de forma compulsória procurou refúgio em países como a França, Inglaterra e Holanda. A eclosão da II Guerra Mundial contribuiu para elevar sobremaneira o número de refugiados e tornar mais dramática a situação destas populações.

Mesmo durante o transcurso da Guerra, produziram-se algumas avaliações sobre os possíveis rumos da economia mundial; nelas, a reorganização da produção perpassava por uma mudança da "vocação" econômica de alguns dos países do continente americano. Neste novo quadro:

\section{A presente guerra, como to-} das as grandes guerras, com o deslocamento dos centros industriais que elas trazem, necessariamente, consigo (...) provocará correntes de migração cujo volume dependerá, em primeiro lugar, mas não exclusivamente, das portas fechadas ou abertas dos países de destino. O centro de gravidade da economia mundial passará, ao que parece, da Europa para a América. (...) Isto não pode ficar sem influência sobre o caráter desse Continente, como virtualmente, um escoadouro nha) central para a imigração de outros continentes e, em particular, da Europa (Fischlowitz, 1943).

Assim, podemos perceber a associação entre um intenso e potencial deslocamento populacional provocado pela Guerra e a nova reorganização econômica que emergiria após o conflito. Nessa perspectiva, há uma estreita relação entre a chegada de imigrantes refugiados de guerra no Brasil nos anos que se seguiram ao fim da II Guerra Mundial e os novos contornos da imigração para o país nesse mesmo período, com a intensificação de um processo de acumulação capitalista de base urbano-industrial.

$\mathrm{O}$ número de refugiados durante a II Guerra Mundial, tanto na Europa quanto no Oriente é bastante controverso. As cifras geralmente variam entre 8 milhões até 70 milhões, dependendo da fonte consultada.' De qualquer forma, houve, durante este conflito, deslocamentos em massa de populações que fugiam do avanço nazista e ao mesmo tempo, um deslocamento forçado, realizado por agentes dos Estados totalitários para fazendas e fábricas, que utilizavam pessoas para o trabalho escravo ou sua colocação em campos de concentração. O quadro abaixo demonstra dados aproximados destas duas formas de deslocamentos em 1942 (ONU, 1950).

De acordo com os critérios da Organização Internacional de Refugiados (O. I.R.)

Deslocamento produzido por fuga de processos de ocupação de territórios (exceto dados da Alema-

\begin{tabular}{l|l} 
Países de emigração & Quantidade \\
Países Bálticos & 255.000 \\
Bélgica e Luxemburgo & 767.520 \\
Tchecoslováquia & 1.275 .750 \\
França & 3.302 .000 \\
Alemanha (colonos) & 1.700 .000 \\
Itália & 575.000 \\
Holanda & 1.537 .000 \\
Polônia & 10.400 .000 \\
lugoslávia & 657.417
\end{tabular}

Deslocamento induzido porforças de ocupação

Para a Alemanha

Para a Polônia

Para a Rússia

6.687 .000

2.421 .000

917.000

Para um destes três paises

(dados imprecisos)

Para a França

634.000 
eram considerados refugiados:

* vítimas dos regimes nazistas e fascistas;

* republicanos espanhóis e outras vítimas do regime falangista na Espanha;

* pessoas que eram consideradas como refugiados antes da eclosão da Segunda Guerra Mundial;

* pessoas que foram obrigadas pelos regimes nazista ou fascista ao trabalho forçado, ou que foram deportadas de seus países por motivos raciais, religiosos ou políticos;

* pessoas que estão fora de seus países de origem ou de antiga residência e que não desejam ou não podem aproveitarse da proteção dos respectivos governos (Comissão Brasil-O.I.R., 1949).

Após a II Guerra Mundial, houve o retorno da grande maioria destas populações para suas regiões de origem, entretanto, dados da O. I. R. apontam que em julho de 1947 havia aproximadamente 1.000 .000 de refugiados na Alemanha e Áustria ocupadas pelas forças aliadas. Destes, a grande maioria não desejava voltar para suas regiões de origem.

Neste momento, a O.I.R., órgão ligado às Nações Unidas, passou a encarregar-se da repatriação destes refugiados ou da imigração para outros países. Até junho de 1949, 436.969 refugiados haviam sido recolocados através do processo de imigração, conforme o quadro abaixo (ONU, 1950):

$\begin{array}{lc}\text { País } & \text { Quantidade } \\ \text { Inglaterra } & 82.262 \\ \text { Israel } & 121.861 \\ \text { Estados Unidos } & 68.677 \\ \text { Canadá } & 66.256 \\ \text { Austrália } & 54.079 \\ \text { França } & 35.031 \\ \text { Argentina } & 26.968 \\ \text { Brasil } & 19.685 \\ \text { Venezuela } & 12.101 \\ \text { México/Peru/Paraguai } & 28.881\end{array}$

Havia uma compreensão, por parte dos Estados que compuseram a formação da ONU, de que o processo de paz só seria efetivado se ele também levasse em consideração o problema dos refugiados de guerra. O novo mapa da Europa e a desorganização econômica após o conflito, im-

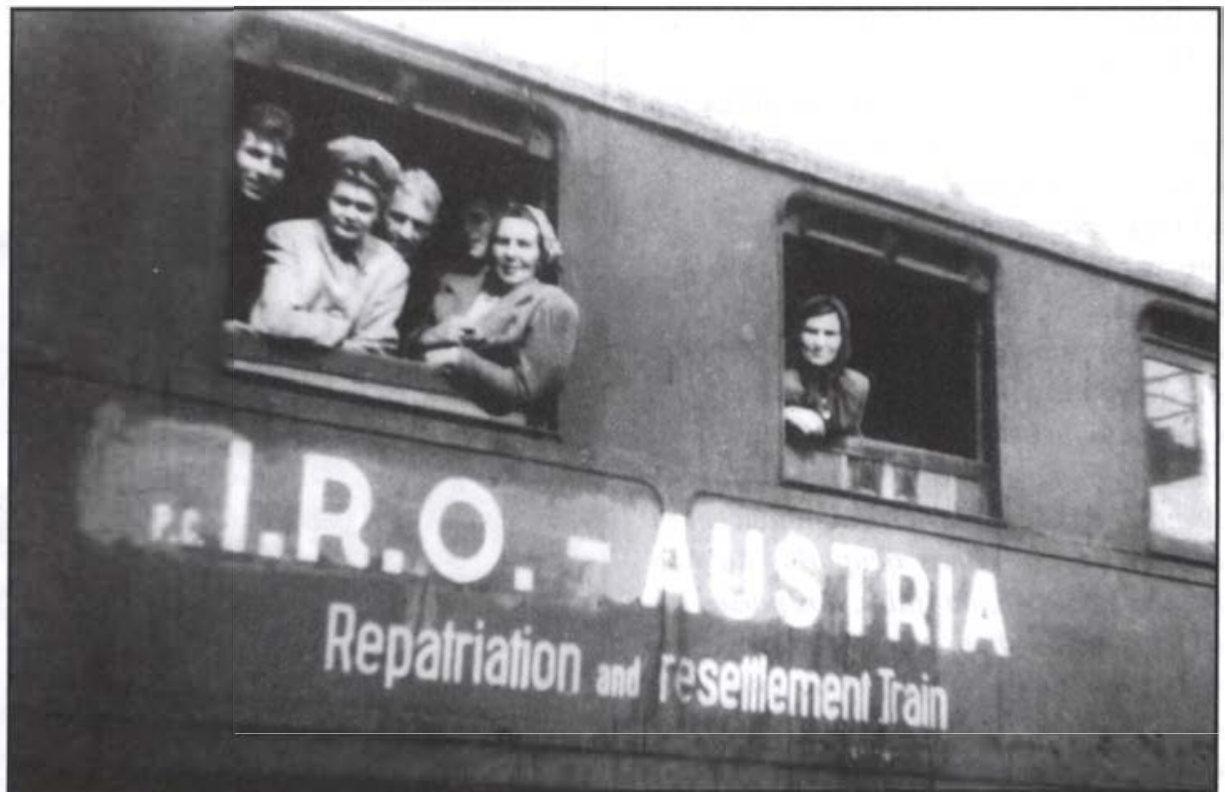

Acervo do Memorial do Imigrante - SP. Deslocados de guerra russos deixando campo de refugiados na Áustria, em 1948, com destino ao Porto de Hamburgo (Alemanha), de onde embarcariam para o Brasil.

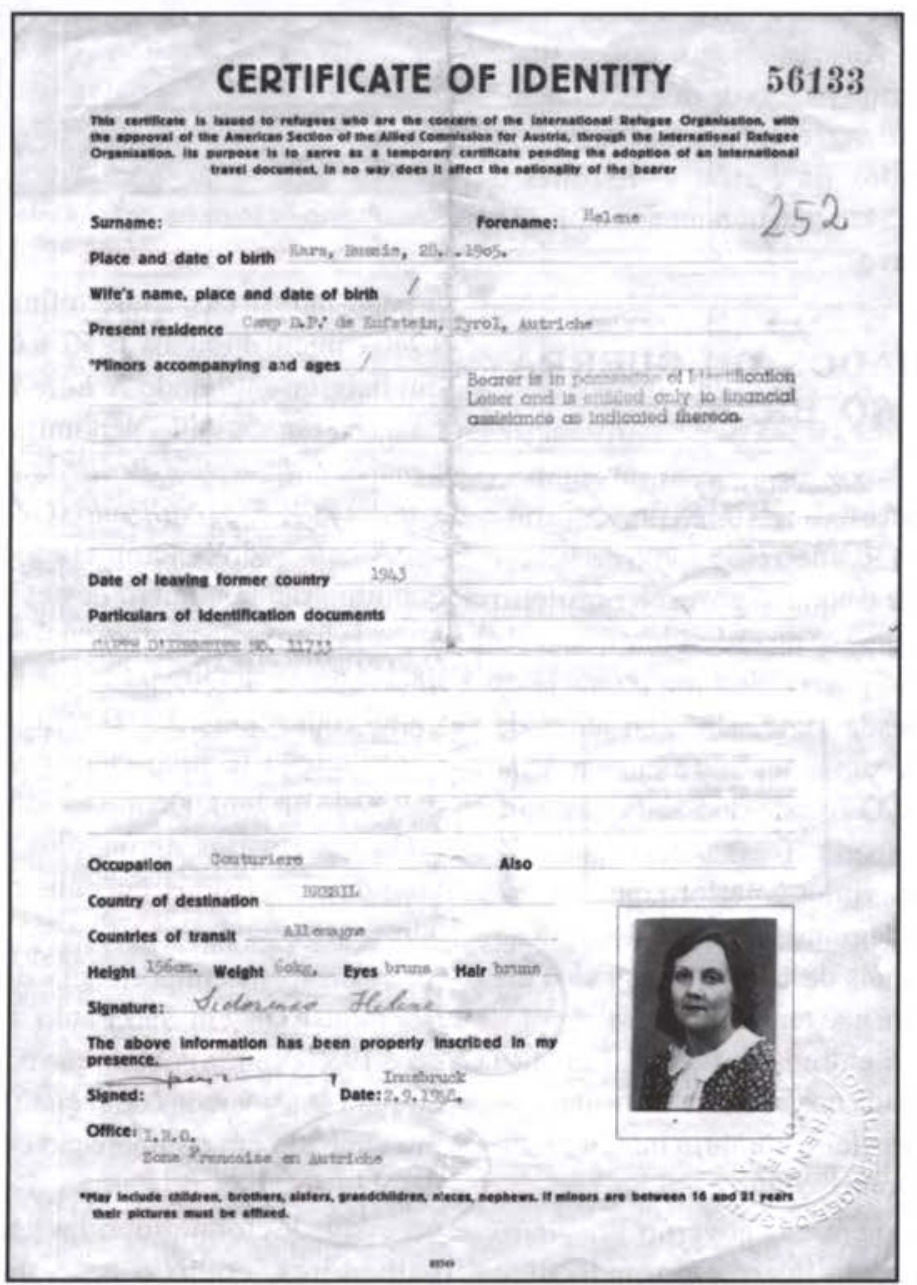

Certificado de Identidade expedido pela O. I.R. Nele, além dos dados de identificação do refugiado, consta a pretensão de emigrar para o Brasil. Este certificado era utilizado tanto para o trânsito do refugiado pela Áustria e Alemanha (já que o embarque para o Brasil se dava em portos da Alemanha) quanto para o pedido de visto em passaporte, necessário para a entrada do imigrante no país. 
pediam o retorno integral da população refugiada.

Neste sentido, um novo processo emigratório/imigratório deveria ser realizado de forma coordenada. Agências como a O.I.R. exerceram papel fundamental no processo de repatriação e recolocação desta população. A administração da O.I.R. era composta por um conselho formado de delegados das nações-membros.(...) Com sede em Genebra, Suiça, a O.I.R. possuía um quadro de 2.563 funcionários de 38 nacionalidades, estes trabalham em 31 escritórios das zonas ocupadas da Alemanha e Áustria, na Itália, nos países europeus que recebem imigrantes, nas Américas e no Médio e Extremo Oriente. Este quadro era acrescido por 3.156 funcionários recrutados no local das ativida$\operatorname{des}(\mathrm{ONU}, 1950)$.

Até junho de 1949, 418.271 pessoas permaneciam em campos de refugiados na Alemanha e Áustria, destes, pouco mais de 104 mil eram judeus de diversas nacionalidades, 113.900 eram poloneses, 93.686 eram oriundos da Letônia, Estônia e Lituânia, 60.342 eram ucranianos e 21.271 eram iugoslavos.

\section{REFUGLADOS DE GUERRA NO BRASIL}

Em 1948 foi formada uma comissão mista Brasil - O.I.R. (decreto 25.796 de 10-111948) a partir da qual o governo brasileiro comprometia-se a receber uma quota de refugiados de guerra, embora o país já os recebesse desde 1947. Um ano antes da formação da comissão, foi veiculada, através do jornal O Estado de São Paulo ${ }^{2}$ que o Brasil receberia 700.000 deslocados de guerra; como vimos anteriormente, os dados de 1949 demonstram que chegaram ao país pouco mais de 19.000 refugiados até 1949. Embora não tenhamos registros precisos sobre a entrada destas pessoas nos anos 1950, nada nos autoriza a afirmar que o governo brasileiro cumpriu integralmente seu compromisso com a O.I.R.

Concretamente, o governo brasileiro estava muito mais interessado em facilitar a imigração de refugiados de guerra com um perfil específico: aqueles que tivessem qualificação para inserir-se em atividades

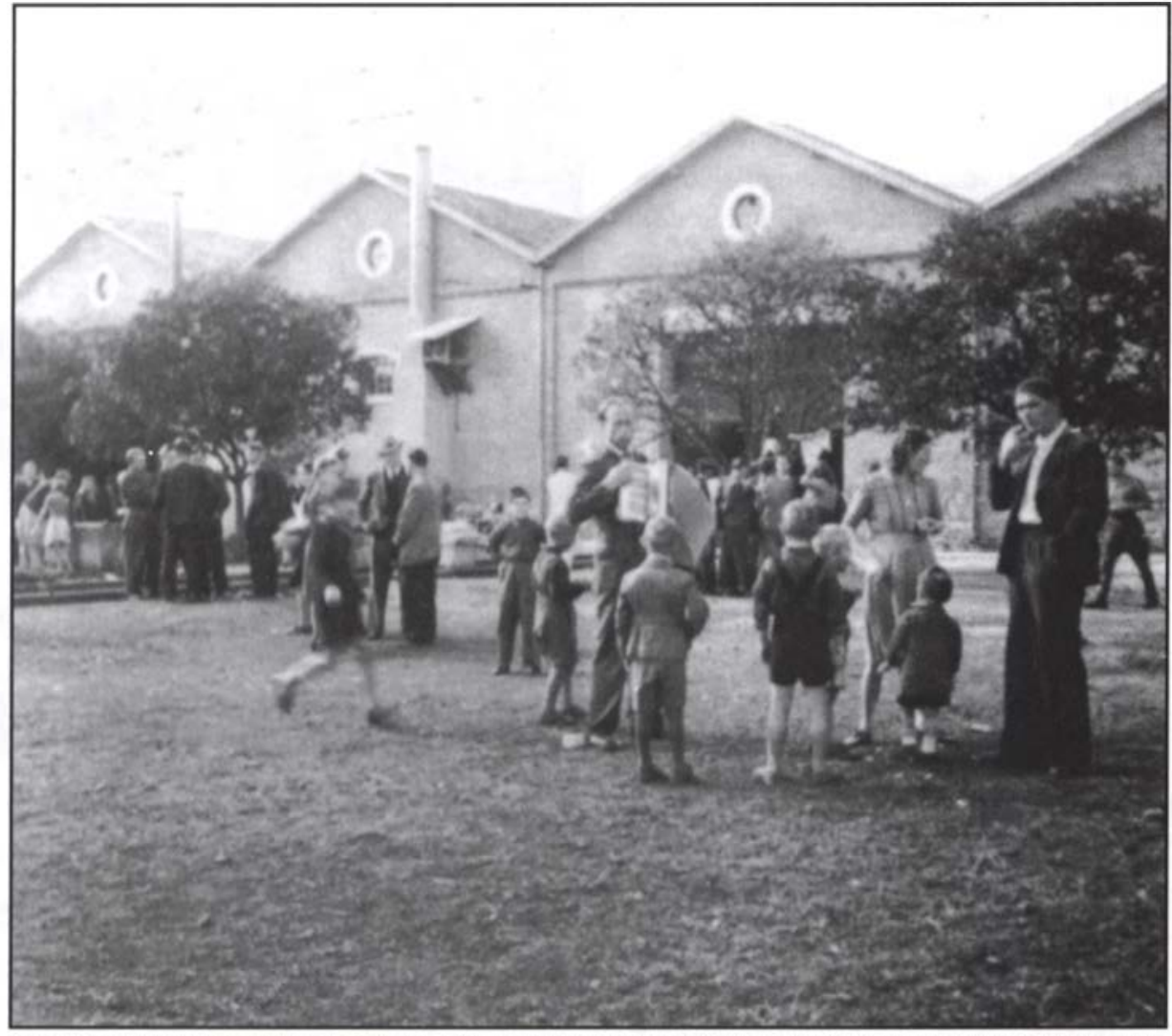

Foto: Acervo do Memorial do Imigrante - SP. Imigrantes na Hospedaria de Campo Limpo Paulista (1947-50)

urbano-industriais. Entre o final dos anos 1940 e início dos anos 1950, a O I.R. edita um boletim intitulado A Elite Esquecida, nele, há um capítulo denominado Vantagens Econômicas e Práticas ao Empregar um D.P. Especializado (ONU, s/d.). ${ }^{3}$

A ênfase do boletim era a de mostrar que um grande número destes refugiados possuía formação profissional especializada. Há uma primeira parte que trata das biografias de alguns destes refugiados e sua contribuição técnico-científica em seus países de origem. Dentre estas biografias, estão: veterinários, agrônomos, cirurgiões, bioquímicos, físicos, engenheiros, professores, arquitetos...

A crescente importância das atividades industriais em São Paulo a partir dos anos 1950 exigia a contratação de uma mãode-obra considerada como qualificada, termo cunhado em comparação com a mãode-obra inserida no campo. Essas novas necessidades foram supridas por estes trabalhadores, como o caso da modista Helene, transferida do campo de refugiados de Kufstein na Áustria (zona de ocupação francesa).
As atividades da O.I.R. em São Paulo eram coordenadas pelo Serviço de Imigração e Colonização e logo depois transferidas para o Departamento de Imigração e Colonização. Em São Paulo, estes refugiados foram alojados na Hospedaria de Campo Limpo, situada na cidade de mesmo nome, próxima à Capital. Ela ocupava antigos galpões que serviam de depósito de café e funcionou até o início dos anos 1950. A Hospedaria de Imigrantes, situada no bairro do Brás em São Paulo esteve neste período ocupada pela Escola de Aeronáutica, sendo devolvida à Secretaria da Agricultura somente em 1951.

Já nos anos 1950, as atividades da O.I.R. são paulatinamente reduzidas. A entrada de refugiados igualmente decresce, entretanto, o perfil da imigração para o Brasil nos anos 1950 e 1960 manteve-se o mesmo. Um acordo entre o governo brasileiro e o Comitê Intergovernamental para Migrações Européias (C.I.M.E.) manteve o fluxo para o país de uma imigração voltada para a inserção nas atividades industriais.

$\mathrm{O}$ acervo do Memorial do Imigrante contém aproximadamente 6.000 documen- 


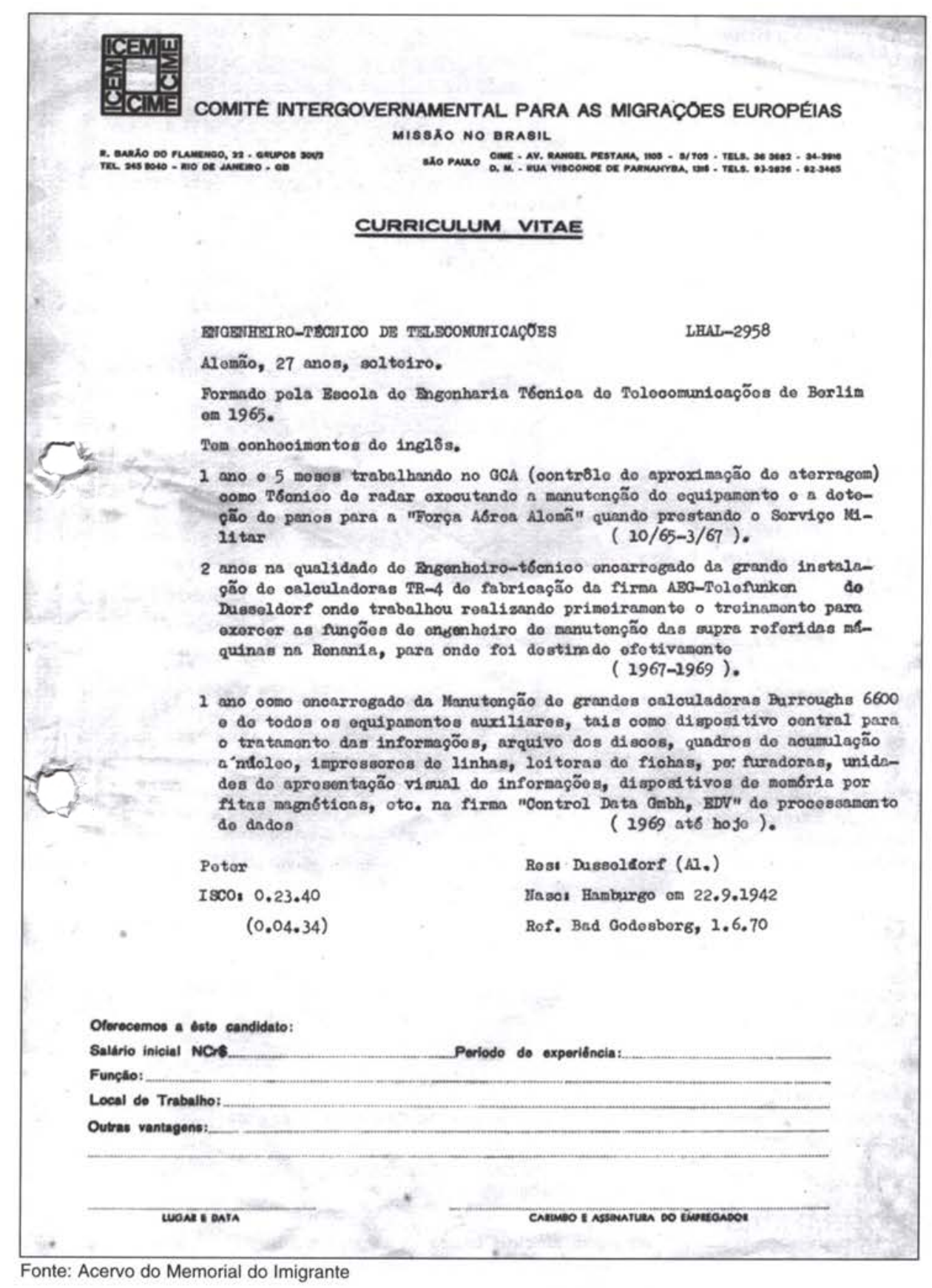

tos entre fichas de registro de imigrantes encaminhados a empresas, curriculum vitae e certificados de identidade de imigrantes entrados em São Paulo por acordo entre a O.I.R. e, posteriormente, entre o C.I.M.E. e o Itamaraty. Esta série esta dividida em duas fases: entre 1947 e o início dos anos 1950, há uma preponderância de refugiados de guerra; após esse período até o final dos anos 1970, temos a entrada de trabalhadores especializados de diversas nacionalidades (italianos, espanhóis, suíços, japoneses...).

\section{CONSIDERAÇÕES FINAIS}

Embora numericamente menor se comparada com a imigração européia e asiática do final do século XIX e início do século $\mathrm{XX}$, a imigração de refugiados de guerra para o Brasil obedeceu a mesma lógica do ponto de vista econômico. Nos anos 1950, a reprodução do capital pressupôs a montagem de uma nova D.I.T. na qual, países cujas economias estavam tradicionalmente assentadas na exportação de produtos primários, passaram a receber financiamen- tos para a montagem de parques industriais e também empresas multinacionais.

Este novo cenário modificou o perfil da imigração, particularmente para São Paulo, dando ênfase à inserção de mãode-obra considerada qualificada. Esta questão mantém presente a necessidade em se produzir estudos sobre o impacto dessa imigração não apenas do ponto de vista econômico, mas também numa perspectiva sócio-cultural. Alguns estudos como o de Sônia Maria de Freitas ${ }^{4}$ buscam resgatar a contribuição de imigrantes de diver- 
sas nacionalidades que vieram para o Brasil no pós-guerra.

Durante muito tempo, a historiografia tratou o tema da imigração numa perspectiva que circunscrevia o mesmo a um período cujo limite estava dado nos anos 1920 e 1930. Este olhar retirou do tema da imigração momentos importantes como a entrada de refugiados de guerra e mesmo as dimensões mais contemporâneas deste processo como a imigração coreana e latina para o país, fenômenos só recentemente trabalhados.

Estes apontamentos têm como objetivo, por fim, recolocar algumas questões sobre a imigração de refugiados de guerra para o Brasil e a necessidade da produção de trabalhos sobre o tema como forma de produzir um quadro compreensivo mais adequado sobre o problema.

* Odair da Cruz Paiva é historiador e membro da equipe técnica do Memorial do Imigrante.

\section{NOTAS}

1. Ole Just (1948) faz menção a cifra de 14 milhões de refugiados enquanto Estanislau Fischlowitz (1943) aponta para a existência entre 60 e 70 milhōes de refugiados tanto na Europa quanto na Ásia.

2. Edição de 05-07-1947. Artigo intitulado $A$ tragédia dos Deslocados, assinado por Paul Vanorden Shaw.

3. A sigla D.P. é a denominação em inglês para Displaced Person ou em algumas publicações. Dislocated Person; em português foi traduzida como Refugiado ou Deslocado de Guerra.

4. Historiadora do Memorial do Imigrante, atualmente desenvolve trabalho na área de História Oral junto a doze comunidades de imigrantes em São Paulo.

\section{REFERÊNCIAS BIBLIOGRÁFICAS}

Boletim do Departamento Estadual do TrabaIho

(1929) São Paulo. Secretaria da Agricultura, Indústria, Comércio e Obras Públicas, ano 17, n. $69,4^{\circ}$. trim.

Boletim do Dpto. de Imigração e Colonizaçăo (1950) São Paulo. Secretaria da Agricultura, Indústria e Comércio, n.5, dez.

COMISSĀO MISTA BRASIL-OIR. (1949) Dados sobre a comissão mista Brasil-OIR. Rio de Janeiro.

FISCHLOWITZ, Estanislau

(1943). O problema internacional das migraçōes e a paz futura. Revista de Imigração e Colonização. Ano IV, n.4, dez. Ministério das Relações Exteriores. Conselho de Imigraçāo e Colonização. Rio de Janeiro JUST, Ole

(1948) Au dessus des mers et des frontiéres. Le grand mouvement migratoire

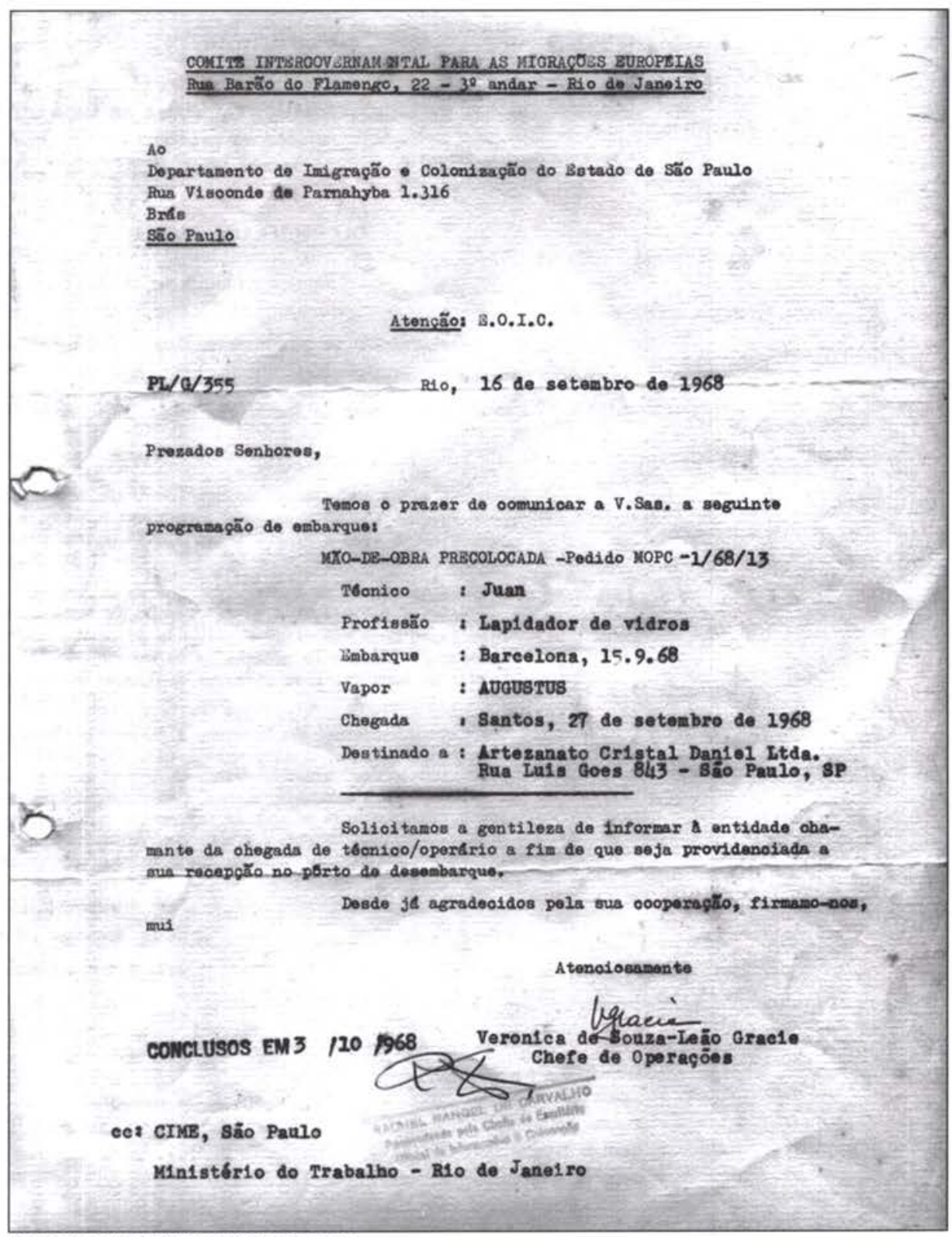

Fonte: Acervo do Memorial do Imigrante

de notre siècle - bases démographiques et economiques de la fédération occidentale. Rio de Janeiro. Organização Cultural Vida.

PAIVA, Odair da Cruz

(2000) Caminhos Cruzados: a migração para São Paulo e os dilemas da construção do Brasil moderno nos anos 1930/50. Tese (Doutorado em História Social) - Faculdade de Filosofia, Letras e Ciências Humanas. Universidade de São Paulo.

PAIVA, Odair da Cruz

(2000) Introdução à História da Hospedaria de Imigrantes em seus Aspectos Institucionais e Guia do Acervo. Săo Paulo: Memorial do Imigrante/Museu da Imigração. (Série Resumos, n. 6)

PAIVA, Odair da Cruz

(2000) Breve História da Hospedaria de Imigrantes e da Imigração para São Paulo. São Paulo: Memorial do Imigrante/Museu da Imigração, (Série Resumos, n. 7)

ORGANIZAÇĀO DAS NAÇŌES UNIDAS

(1950) O problema dos refugiados. Rio de Janeiro

ORGANIZAÇĀO DAS NAÇŌES UNIDAS

(s.d.) A elite esquecida. Organização Internacional de Refugiados. Rio de Janeiro.

Revista de Imigraçăo e Colonização

(1947) Ministério das Relaçōes Exteriores.

Conselho de Imigração e Colonização. Rio de Janeiro. Ano VII, set. n. 3

TRAFT, Donald R. A.

(1935) A Study of International Movements. New York. The Ronald Press Company, 1936. Monthly Summary of the League of Nations. Sept. 